\title{
Quantifying the Delamination of L-shaped Composite Laminates Under Low Velocity Impact Using X-ray Computed Tomography
}

\author{
KENAN CINAR, IBRAHIM GUVEN, FATIH E. OZ \\ and NURI ERSOY
}

\begin{abstract}
Low velocity impact response and failure behavior of L-shaped composite laminates were investigated. The composite laminates with variable thickness, stacking sequences, and corner radius were manufactured using autoclave manufacturing method. Tests were conducted on a custom low velocity impact test set-up. In order to investigate and quantify the internal damage of the samples, x-ray micro-computed tomography technique was used. The results showed that the deflection of cross-ply samples was higher than the unidirectional ones, and as the thickness decreases deflection increases for the same loading conditions. In addition, as the corner radius decreased, the deflection was more pronounced. Delamination migration was observed at the mid-plane of the corner in unidirectional samples while delamination planes largely remained separate and parallel to each other in the crossply samples.
\end{abstract}

\section{INTRODUCTION}

Many composite structures experience damage under conditions of impact loading in aerospace, and automotive applications. One of the critical section of composite structures is sharp curved sections such as L- and C- sections where interlaminar opening stresses are induced and delamination occurs due to impact loading. Thus, impact response and failure characterization of composite structures are vital and need to be investigated.

Kenan Cinar, Namik Kemal University, 59860 Corlu / Tekirdag, Turkey. Ibrahim Guven, Virginia Commonwealth University, Richmond, VA 23284, U.S.A. Fatih E. Oz and Nuri Ersoy, Bogazici University, Bebek 34342, Istanbul, Turkey. 
Extensive experimental [1-7] and computational [2-6, 8-12] research on the response of composites subjected to low velocity impact has been conducted. In these studies, the effect of energy levels [2, 3, 6, 7], stacking sequence [1-3, 7], and impactor shape $[7,10]$ on the damage behavior and the force-displacement response were studied. In order to examine the effect of stacking sequence on the delamination propagation, single-ply and blocked-ply laminates were tested and analyzed $[1,2]$. It was found that the higher critical load in the single-ply laminate leads to a higher delamination threshold and delays the delamination propagation [2]; single-ply laminates are more flexible than blocked-ply laminates, leading to a larger overlapped area of damage [1]. Zouggar et al. [3] studied the response of S-Glass/Polyester composite laminates under low velocity impact. 3-point bending configuration was considered to set the laminates under drop weight impact to examine the effect of energy levels on the bending of the laminates. Here the samples were not clamped to the fixture which is different from the test standard of ASTM D 7136. As the energy levels increased the deflection of laminates was more pronounced. At the initial stage of the curves there were oscillations which are related to the vibrations induced by the contact between plate and the impactor.

Most of the studies have focused on the deformation behavior of flat laminates while there were few studies that consider the curved laminates subjected to static loading [13-16], and low-velocity impact loading [17-20]. Interlaminar stresses causes delamination failure in curved laminates. L-shaped laminates were subjected to static loading using a special loading fixture $[13,16]$ and using four-point bending fixture [15]. Wimmer et al. [13] investigated formation of initial and growth of existing delaminations in laminates made of unidirectional carbon fiber reinforced epoxy. Gozluku et al. [16] studied dynamic delamination in L-shaped laminates. Delamination initiation and propagation were observed using high-speed camera. It was found that the quasi-static shear loading initiates delamination at the curved region which propagates faster than the shear wave speed of the material. Ranz et al. [15] conducted experimental study to examine the interlaminar tensile strength of carbon/epoxy L-shaped laminates. As the laminate thickness increased the interlaminar tensile strength decreased. Also, they used tufting technology to improve the interlaminar tensile strength. In the dynamic loading point of view, impact response of curved composite panels was studied to show the effect of curvature on the impact response and damage propagation [17-21]. Kistler and Waas carried out experimental, numerical and analytical studies to investigate the effect of impactor velocity, panel curvature, thickness, and both in-plane and out-of-plane boundary conditions on the resulting impact force and laminate displacement [18-20]. They showed that as the thickness increases, the peak impact force increases whereas the peak center displacement and contact duration decreases. As the thickness decreased, deformations were more pronounced and curvature effects became increasingly prevalent. Flatter panels led to higher peak forces than curved panels, as well as smaller peak displacements and contact durations. There was no examination about damage initiation and damage propagation in the study [17]. Saghafi et al. studied the effect of preloading on the impact response of curved laminates. It was found that by increasing the preload, the maximum load increased and displacement decreased due to the increase in the stiffness of the curved laminate. Also, examining the back and front surface of the laminates indicate that compression stress at the inner surface confined the propagation of matrix cracks, while tension stress increased it. 
Although there are some studies related to low velocity impact of curved laminates, there are no studies related to impact behavior of L-shaped laminates. Lshaped structures are mainly used in spar structures and consisting of a curved section. In this study the effect of stacking sequence, corner radius, thickness and impact energy on the force history was investigated. Also, x-ray micro-computed tomography (micro-CT) was used to quantify and characterize the damage.

\section{EXPERIMENTAL PROCEDURE}

The L-shaped specimens were made from unidirectional Hexply AS4/8552 carbon fiber prepreg system. For the manufacturing of samples, a male L-shaped steel tool was used as a mold. The prepregs were laid on the outer surface of the tool and cured according to regular autoclave curing method. Two distinct radii of the curved section were used: $6.4 \mathrm{~mm}$ and $15 \mathrm{~mm}$. The composite laminates of 16, 20, and 24 layers with two stacking sequences (unidirectional, and cross-ply) were manufactured. Fibers were oriented towards the sample's legs and along the curved area in the unidirectional (UD) samples. The stacking sequence of the cross-ply (XP) samples was $[0 / 90]_{\mathrm{ks}}$ in which $\mathrm{k}$ corresponds to the number of symmetric layers. The L-shaped panel manufactured was then cut into three test specimens with a width of $25 \mathrm{~mm}$ each using a diamond disc cutter. The dimensions of the specimens were determined using ASTM D6415. The dimensions and the samples manufactured are shown in Figure 1(a) and (b), respectively. The thickness of a layer is $0.180 \mathrm{~mm}$. The sample designation code is given as "Corner Radius - Stacking Sequence - Ply Numbers Energy Level - Sample Number”, for example, R6.4-UD-16-10J-S1.

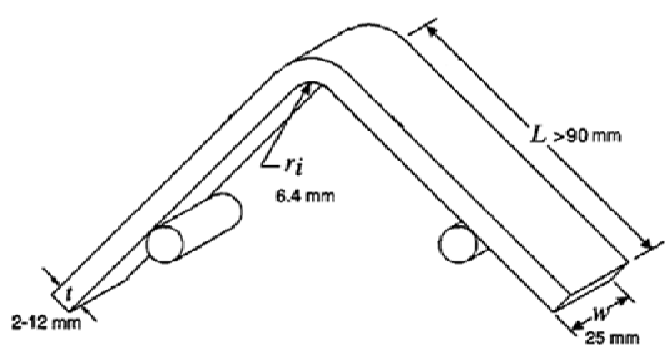

(a)

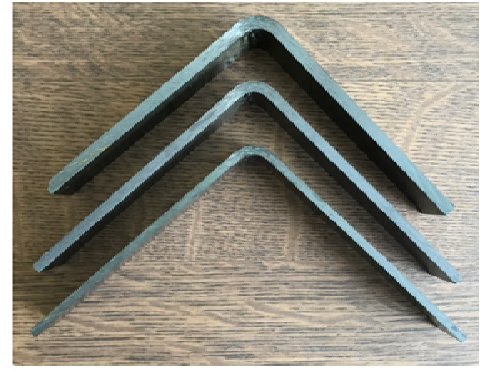

(b)

Figure 1. (a) The dimensions of the samples (ASTM D6415), (b) unidirectional 16, 20, and 24 layered samples manufactured.

The L-shaped composite laminates were subjected to low velocity impact loading using an instrumented falling weight impact test set-up. The experimental test set-up is shown in Figure 2. A piezoelectric load cell is attached to the impactor. The signal of the load cell was acquired at $36 \mathrm{kHz}$. The hemispherical head of the load cell had a diameter of $12.7 \mathrm{~mm}$. The specimens were placed carefully on two steel bars, as shown in Figure 1(a). The span length was $100 \mathrm{~mm}$. A hemispherical tub with diameter of $12.7 \mathrm{~mm}$ was used to impact the samples at their centers in the out-of- 
plane direction with kinetic energies of $10 \mathrm{~J}$, and $13.2 \mathrm{~J}$ with the same dropping height of $0.651 \mathrm{~m}$. The test set-up had a catch mechanism to eliminate repetitive impact. During the tests a 12 MP high definition camera was used to capture images (resolution of 1280x720 pixels). Image recording rate was 120 images per second. In order to reveal and analyze the vertical displacement of the laminates, GOM correlate software was used.

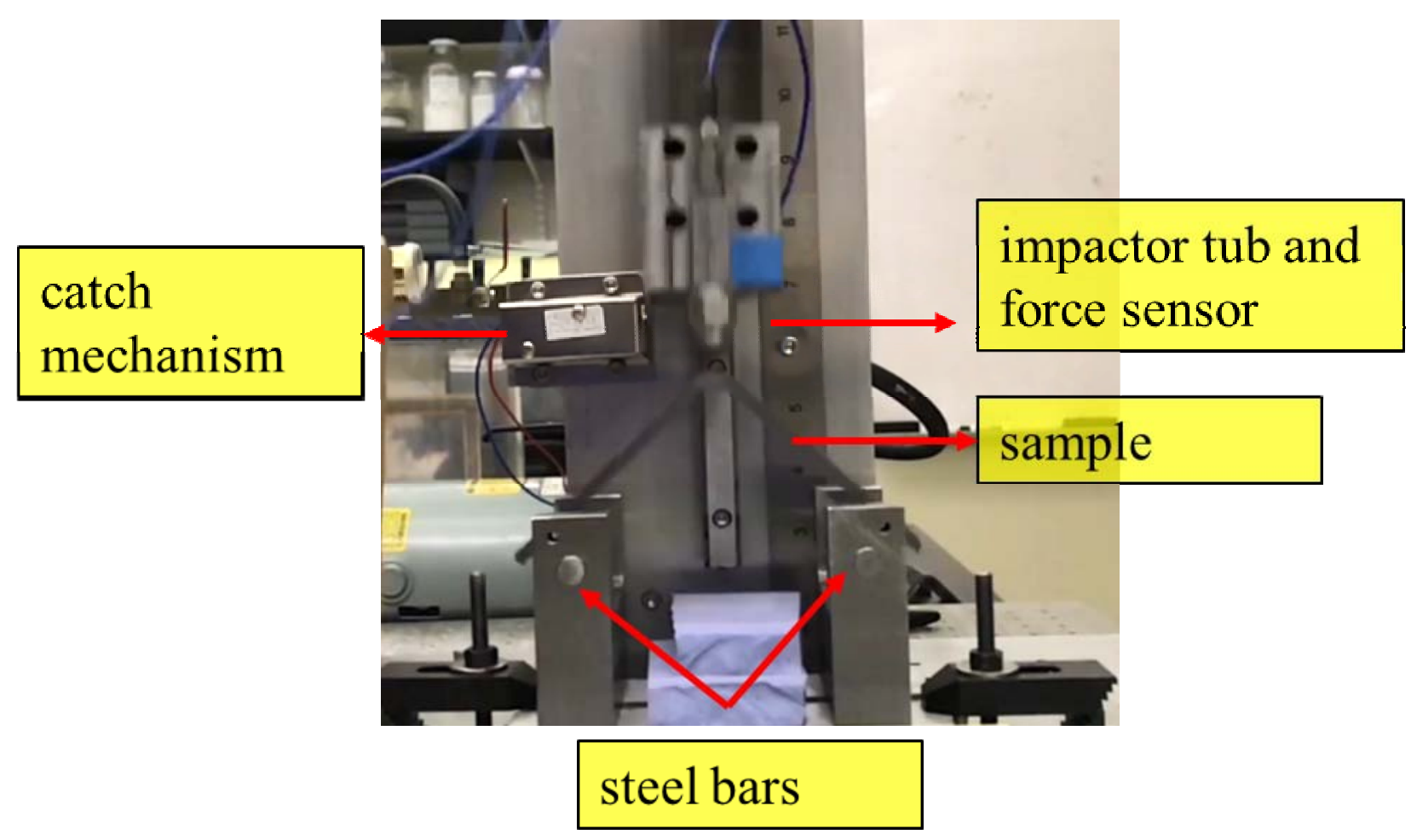

Figure 2. Low velocity impact test set-up.

After the low velocity impact testing, x-ray micro-CT was used to measure and record the internal damage of the composite laminates. Before scanning all samples were immersed into a dye-penetrant and held in a vacuum chamber for ten minutes, which resulted in complete solution penetration in all available openings. Zinc iodide solution was used as the dye-penetrant, which has a high absorption coefficient in comparison to the constituents of the composite materials i.e. carbon fiber and epoxy. The zinc iodide solution was a mixture of alcohol $(10 \mathrm{ml})$, distilled water $(10 \mathrm{ml})$, and Kodak photo solution $(1 \mathrm{ml})$ and zinc iodide powder $(60 \mathrm{~g})$. Excess dye-penetrant was eliminated. The samples were scanned with a SkyScan 1173 X-ray microtomograph with the same resolution of $34.87 \mu \mathrm{m}$ and an angle step of $0.15^{\circ}$. The X-ray tube voltage and current were set to $80 \mathrm{kV}$ and 100 microampere, respectively. The reconstruction was performed using NRecon commercial software. 


\section{RESULTS AND DISCUSSION}

\section{Influence of Thickness and Stacking Sequence}

In order to examine the effect of thickness and stacking sequence on the impact force history, three different thickness $(16,20$, and 24 ply), and two different stacking sequence (UD and XP) were considered. Impact force histories under $13.2 \mathrm{~J}$ are depicted in Figure 3 for 24 ply UD and XP, 20 ply UD and XP, and 16 ply UD laminates. The corner radius of the samples tested was $6.4 \mathrm{~mm}$. Force history was represented up $10 \mathrm{msec}$ to see the initial portion of the curve in detail. The force-time curve had three characteristic regions; initial peak, a linear region, and sudden drop region for cross-ply laminates. On the other hand, these regions were more pronounced when thickness was reduced in unidirectional laminates.

Force, velocity and displacement history are shown in Figure 4(a), 4(b), and 4(c), respectively. Velocity and displacement histories were found by single and double integration of force history with respect to time, respectively. It can be seen in the velocity history that the slope of the curve changes in time up to where velocity is zero, which represents the maximum deformation. 16 ply UD laminates did not show the second change in the slope. As the thickness decreased the duration of the maximum deformation occurrence decreased. Also, as the thickness decreased the maximum deformation increased. Initial impact force peak values increased when the thickness of the laminates increased. This trend can be seen in Figure 5. The 16 ply UD laminate had the lowest rebound velocity, which might be the indication of large damage.

Figure 6 shows force history of 16 ply UD and 16 ply XP laminates subjected to $10 \mathrm{~J}$ impact energy. UD laminates gave higher initial peak force values as compared to the XP laminates except for 24 ply laminates subjected to $13.2 \mathrm{~J}$ impact energy, shown in Figure 5. Same trend was found as the corner radius was increased. Figure 7 indicates the initial peak force values for UD and XP laminates that have corner radius of $6.4 \mathrm{~mm}$ and $15 \mathrm{~mm}$.

Figure 8 shows force, velocity and displacement history of UD and XP laminates with 16 and 24 ply. The laminates were subjected to $10 \mathrm{~J}$ and $13.2 \mathrm{~J}$ impact energy. The main difference is in the velocity history in that the slope abruptly changes three times in XP laminates while it changes two times in UD laminates up to maximum deflection, where velocity is zero. Also, the duration up to the maximum deflection was smaller in the UD laminates as compared to the XP laminates but the maximum deformation was higher in the XP laminates.

The maximum vertical displacement of 24 ply XP and UD laminates and 16 ply XP and UD are shown in Figure 9 and 10, respectively. The images were captured at the maximum vertical displacement, where velocity is zero. XP laminates deformed more than UD samples. The vertical displacements of the tup were $39.797 \mathrm{~mm}$ and $26.595 \mathrm{~mm}$ for XP and UD laminates, respectively. XP laminates had more delamination regions than UD laminates shown in the figures. 

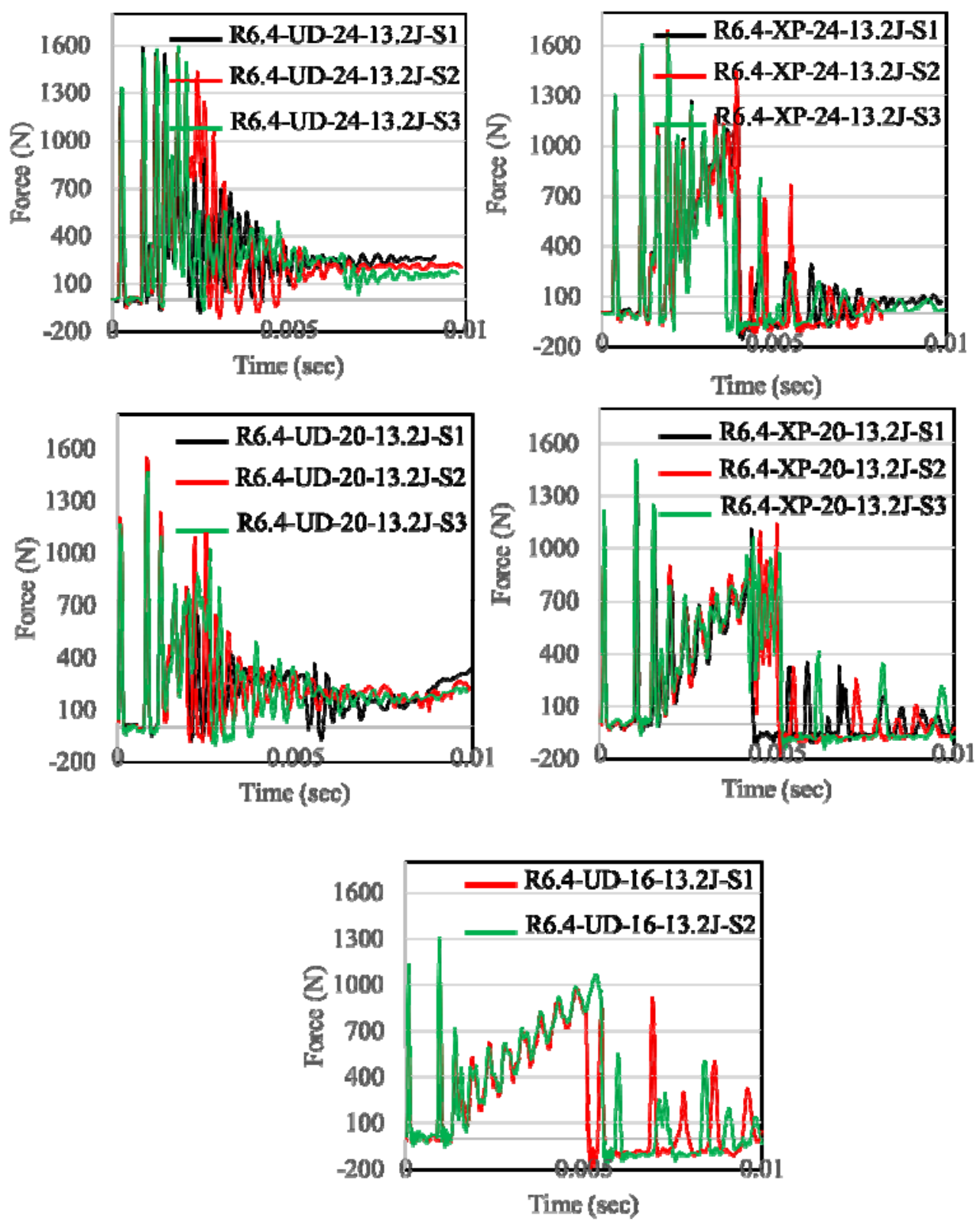

Figure 3. Force-time history of 24 ply UD and XP (top), 20 ply UD and XP (middle), and 16 ply UD (bottom) laminates subjected to impact energy of 13.2J. 

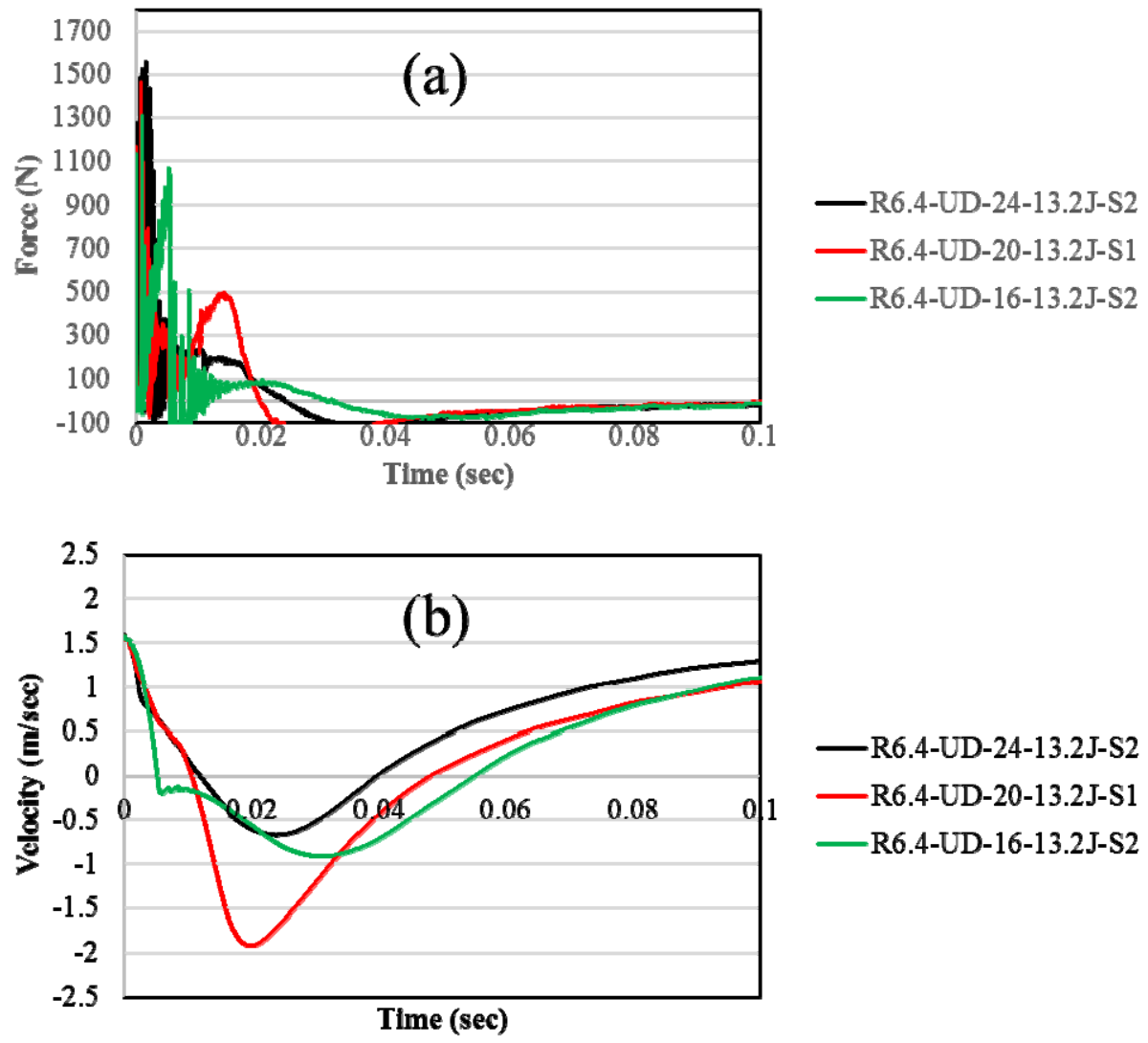

- R6.4-UD-24-13.2J-S2
- R6.4-UD-20-13.2J-S1
R6.4-UD-16-13.2J-S2

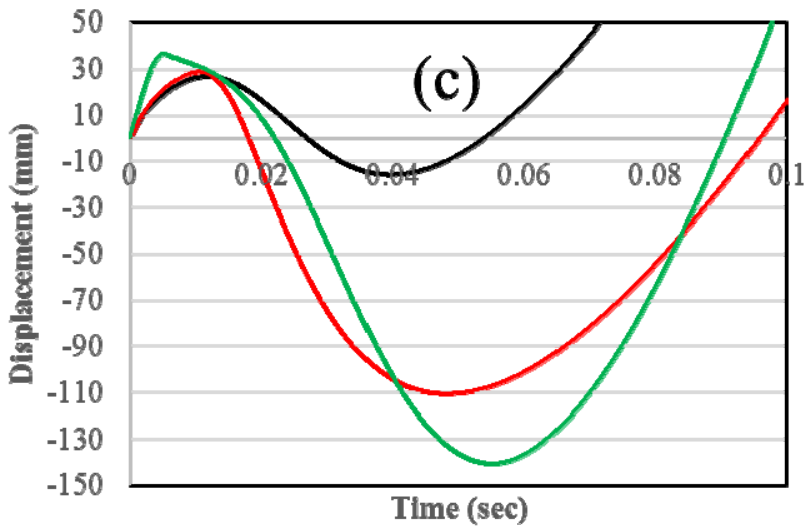

-R6.4-UD-24-13.2J-S2

-R6.4-UD-20-13.2J-S1

—R6.4-UD-16-13.2J-S2

Figure 4. Force (a), velocity (b), and displacement (c) history for 24, 20, and 16 ply laminates subjected to 13.J impact energy. 

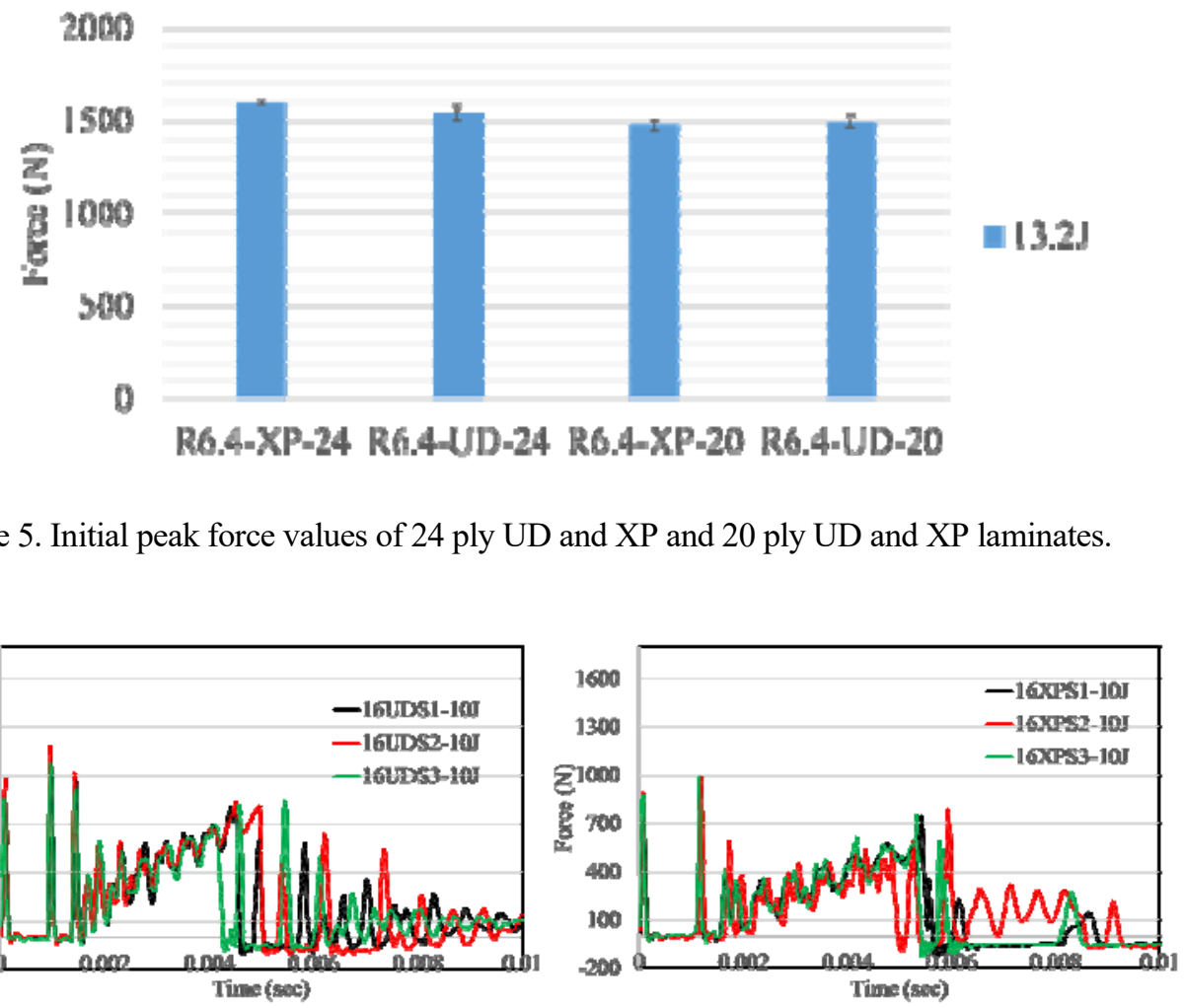

Figure 6. Force-time history of 16 ply UD (left) and 16 ply XP (right) laminates subjected to impact energy of $10 \mathrm{~J}$.

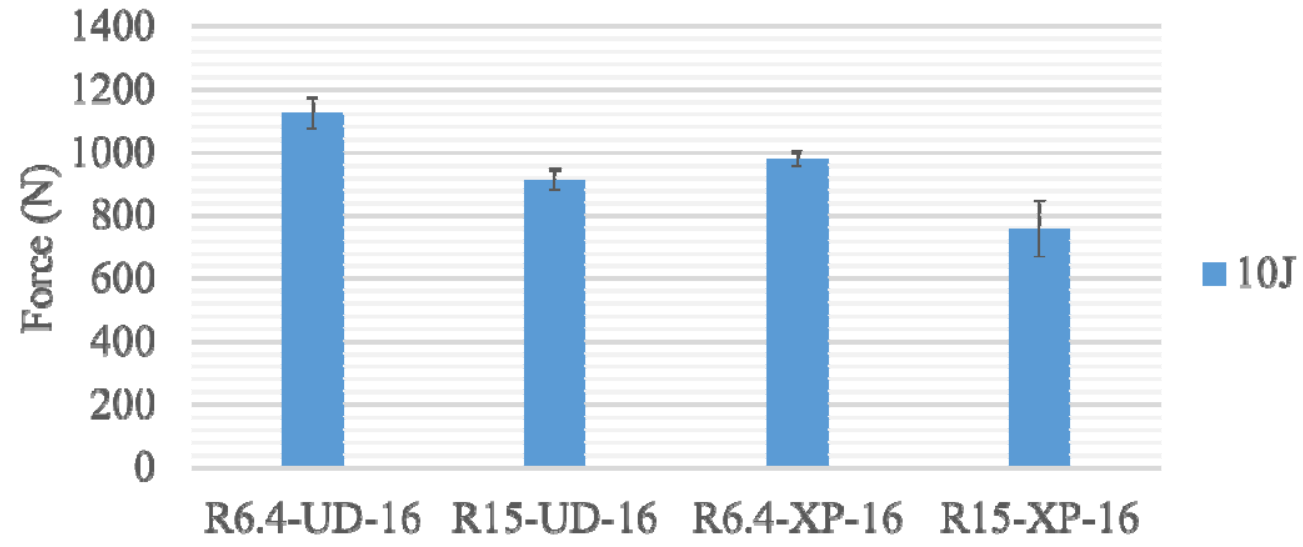

Figure 7. Initial force peak values of 16 ply UD and XP laminates with two corner radius of $6.4 \mathrm{~mm}$ and $15 \mathrm{~mm}$. 

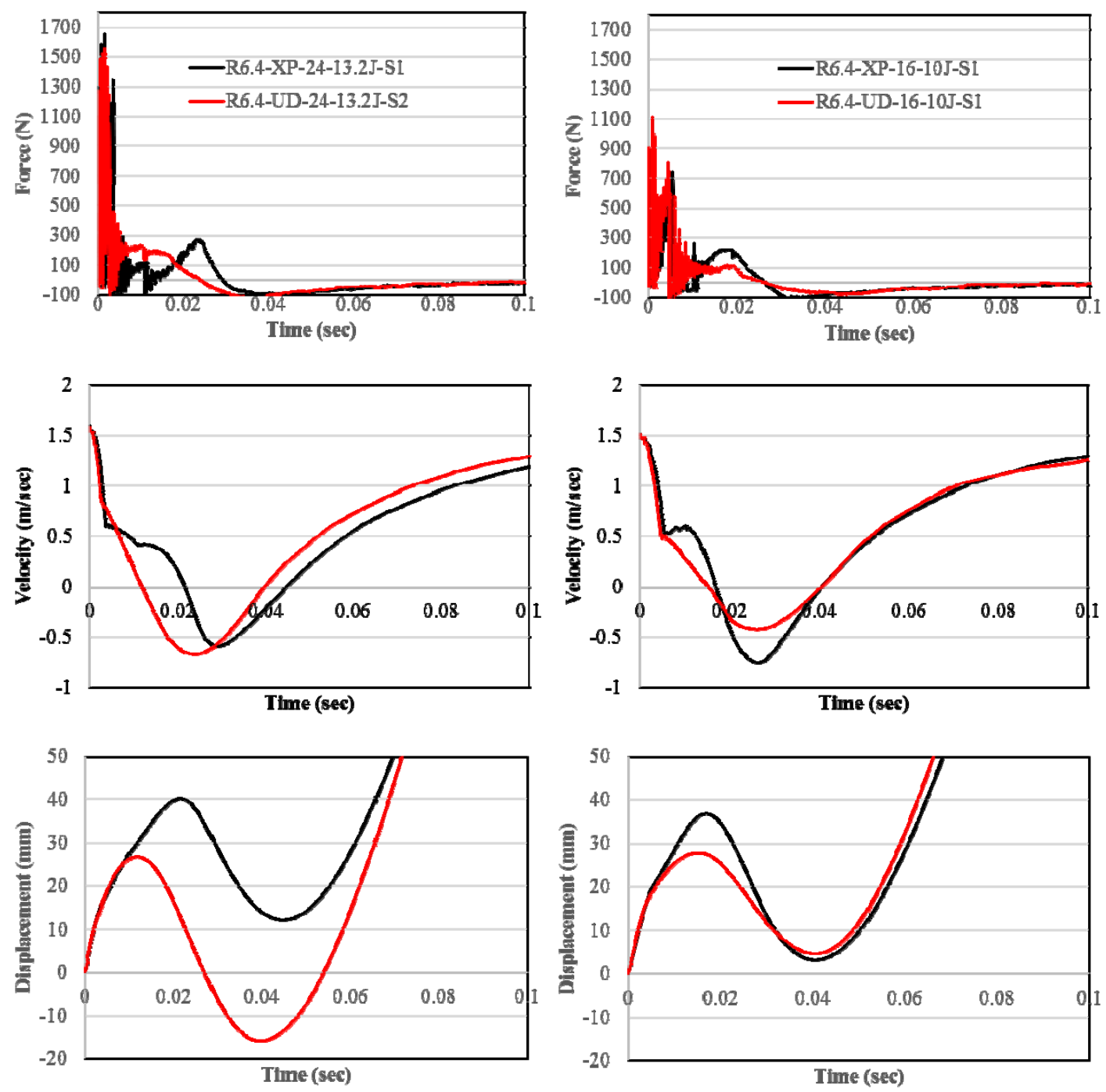

Figure 8. Force-time history of 24 ply UD and XP laminates subjected to $13.2 \mathrm{~J}$ impact energy (left), and 16 ply UD and XP laminates subjected to $10 \mathrm{~J}$ impact energy (right). 


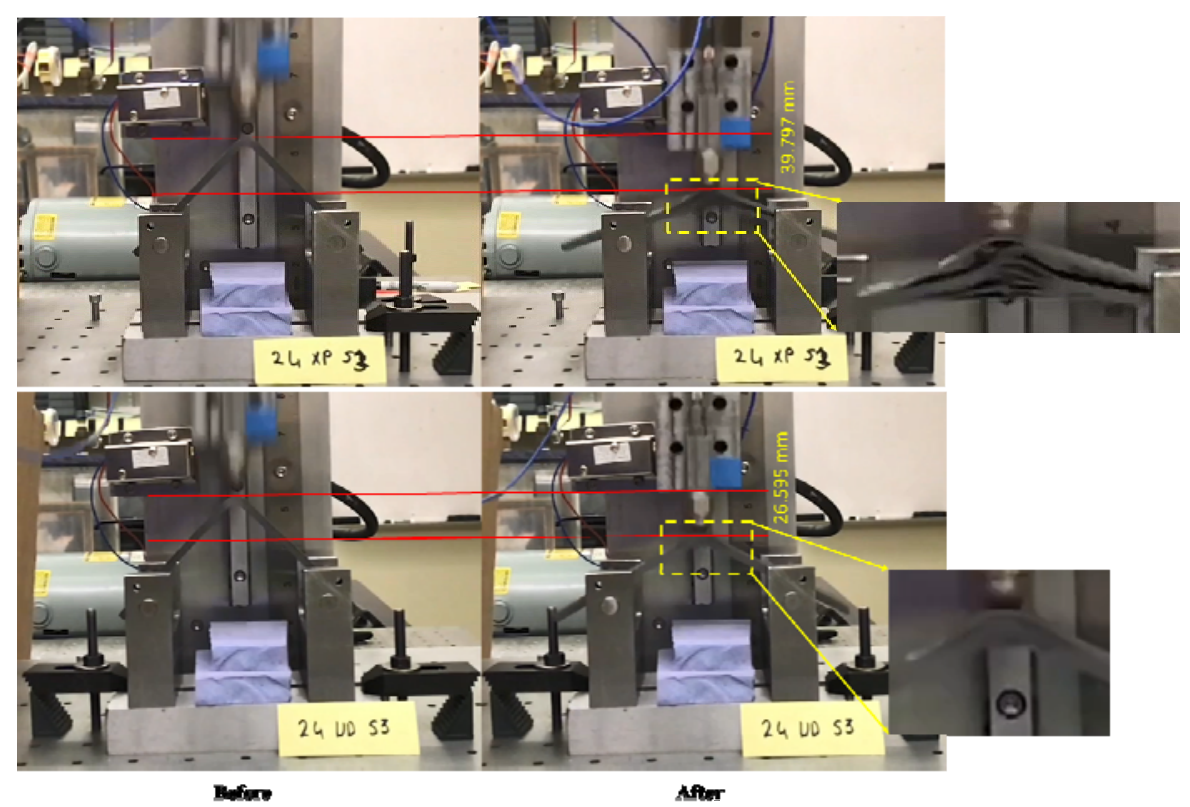

Figure 9. Deformation of 24 ply UD and XP laminates subjected to impact energy of 13.2J.

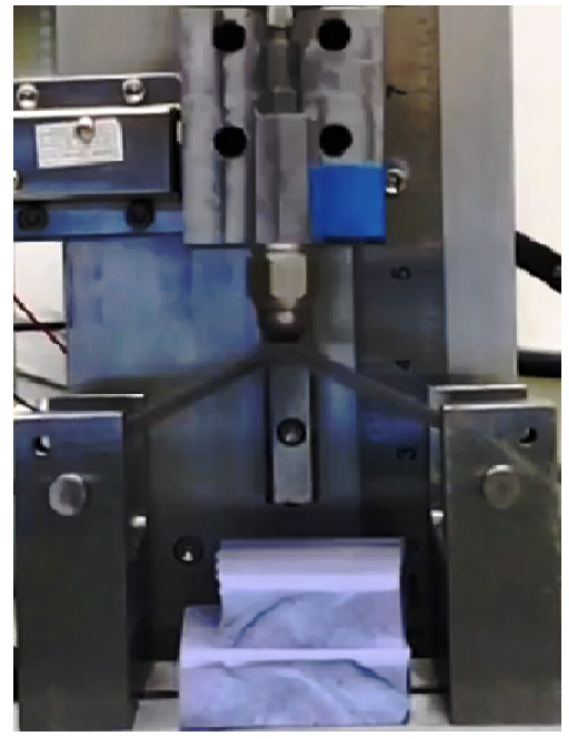

(a) R6.4-UD-16-10J-S1

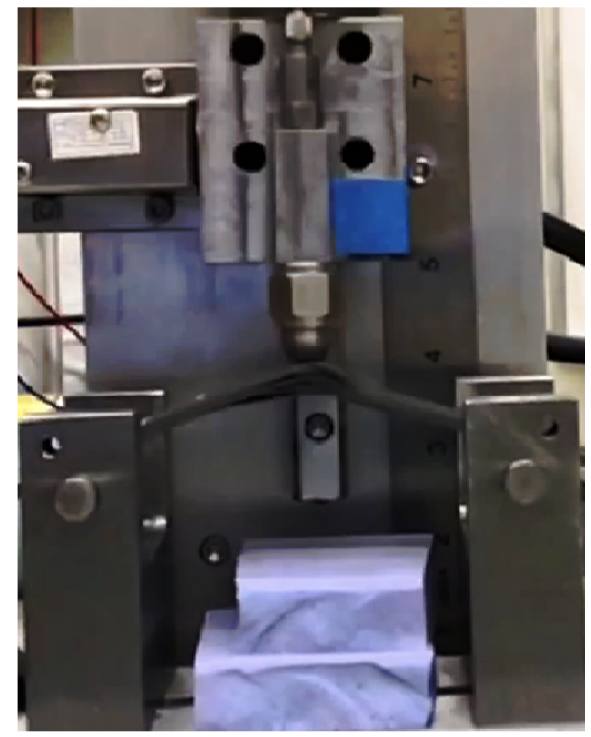

(b) R6.4-XP-16-10J-S1

Figure 10. Deformation of 16 ply UD and XP laminates subjected to impact energy of 10J.

Micro-CT images of 24 ply UD and XP laminates are shown in Figure 11. It can be seen clearly in A-A section (mid plane of the corner) of UD samples that there is delamination migration but on the other hand delamination planes are parallel to each other in the XP samples upon examination of A-A section of the 24 ply XP sample. The difference in the damage morphology of UD and XP laminates can be seen in Figure 11 and 12. The damage in the UD laminates was localized at corner region while the damage extended to the arms in the XP laminates. Also, there was a " $\mathrm{C}$ shape" damage, like a wave, in the arms of the XP laminates. This damage morphology did not change as the impact energy and corner radius was changed. 


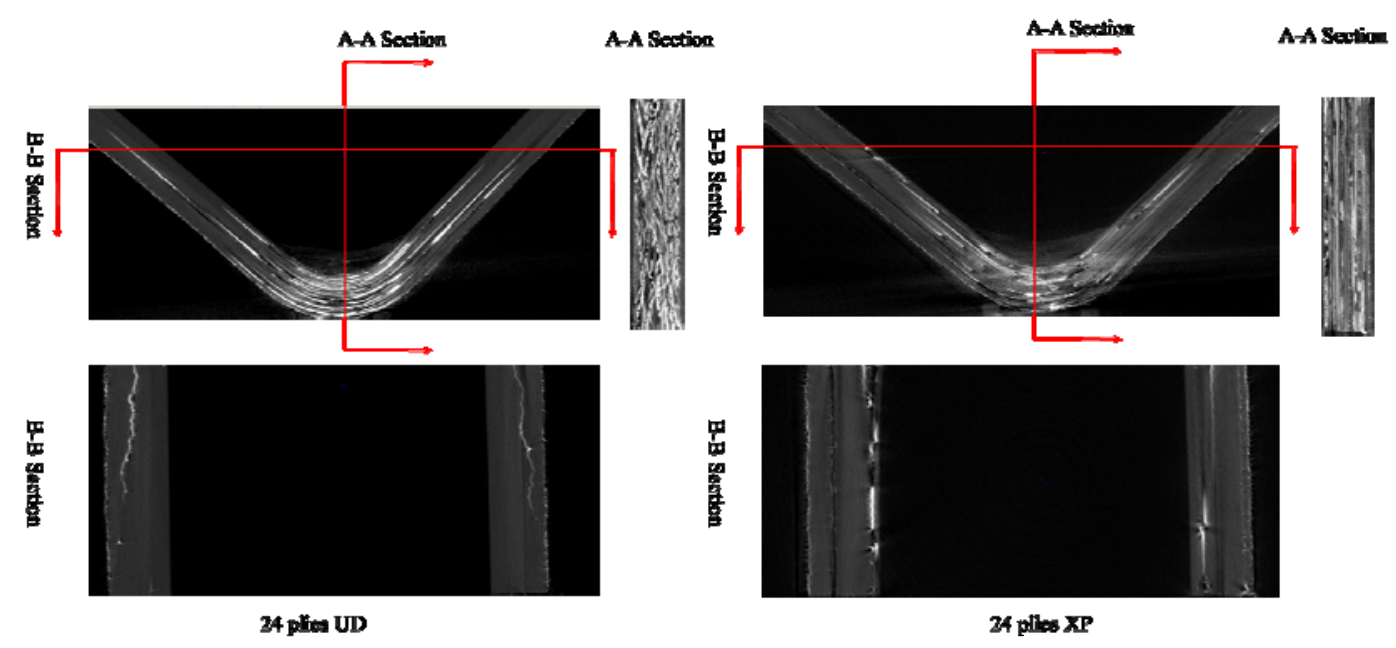

R6.4-UD-24-13.2J

R6.4-XP-24-13.2J
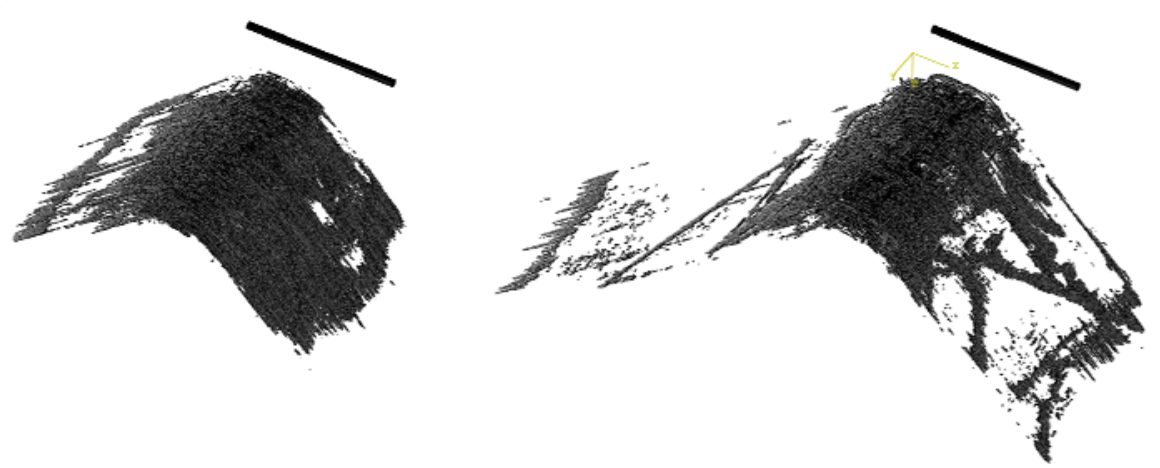

$20 \mathrm{~mm}$
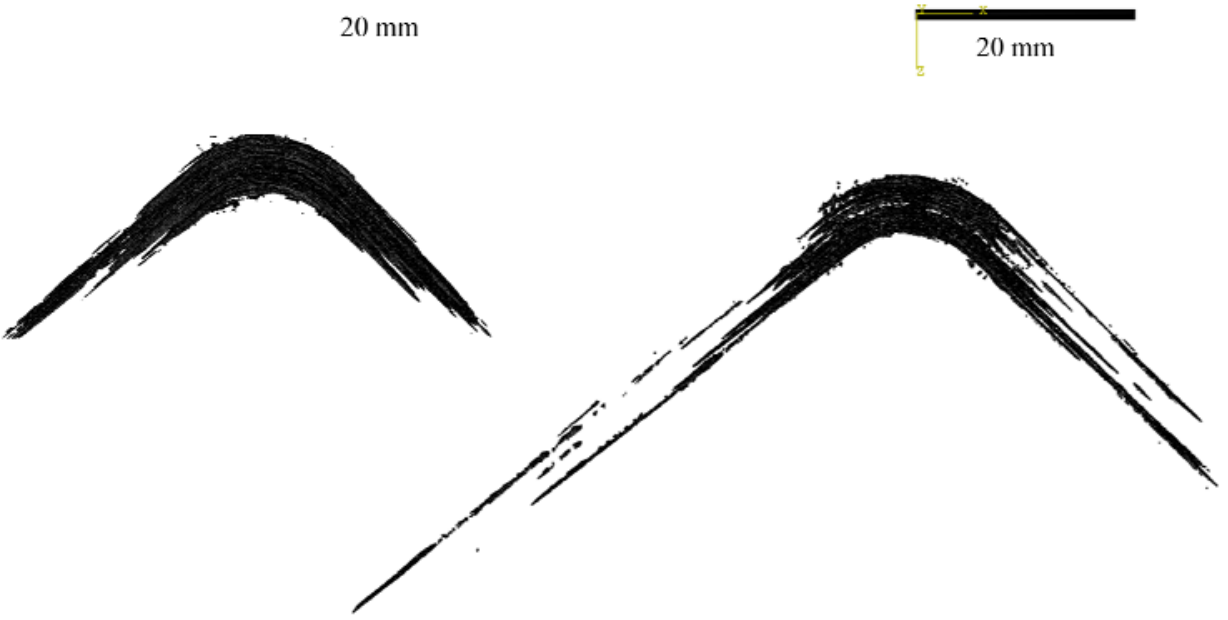

Figure 11. Micro-CT images of 24 ply UD (left) and XP (right) laminates. 


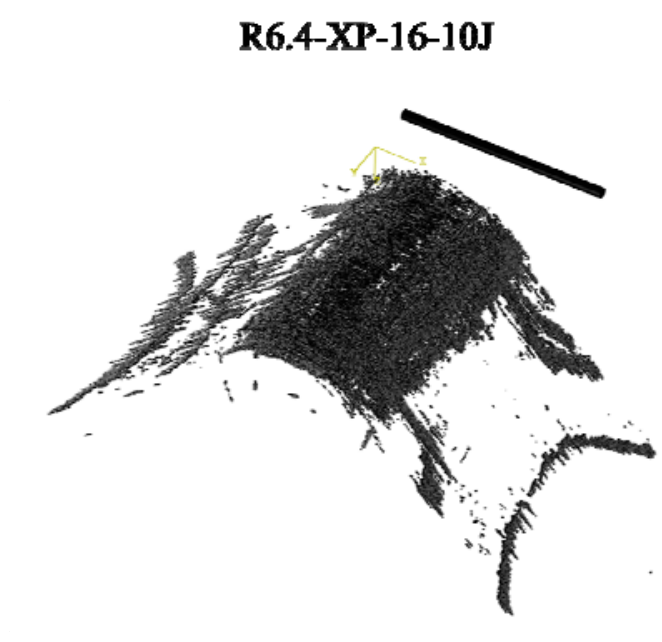

R6.4-UD-16-10J
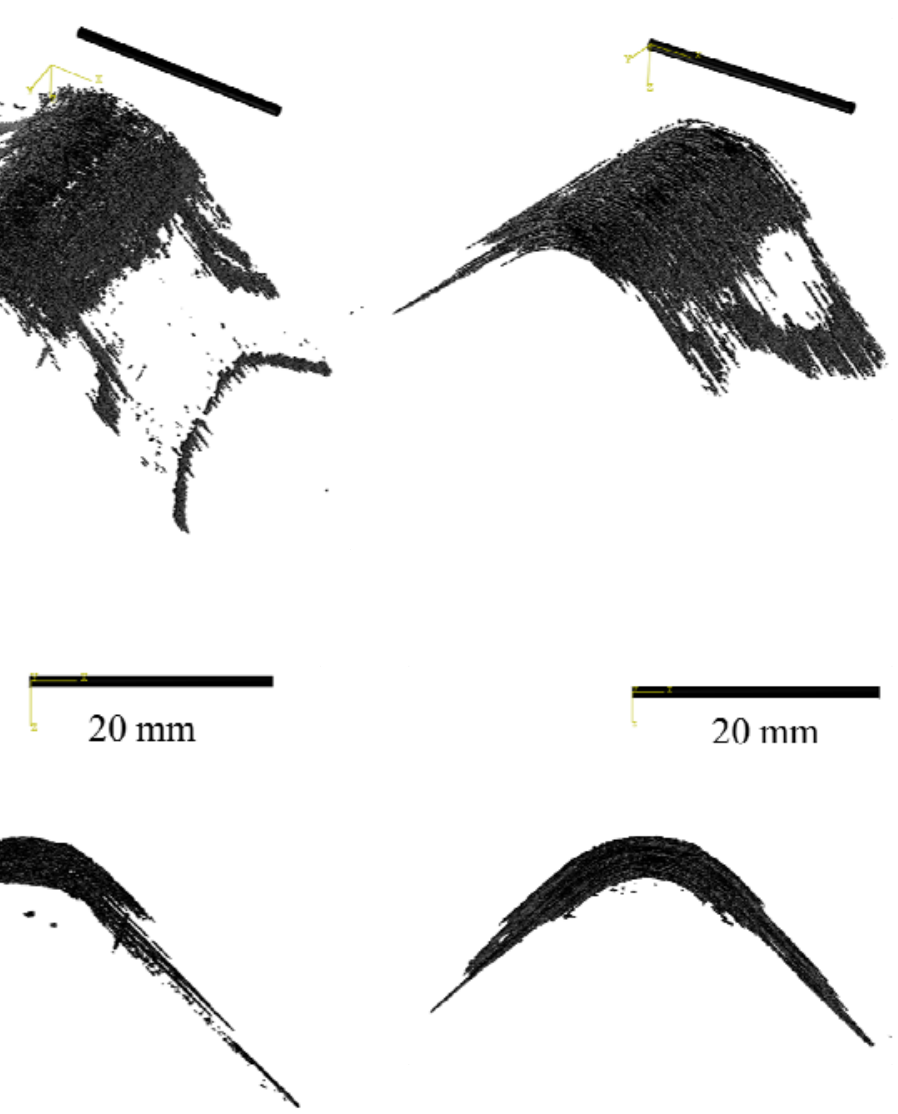

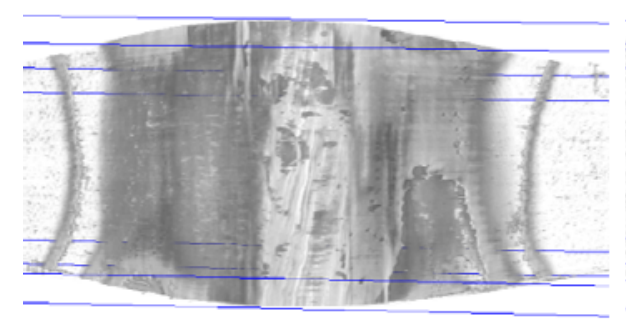

R15-XP-16-10J

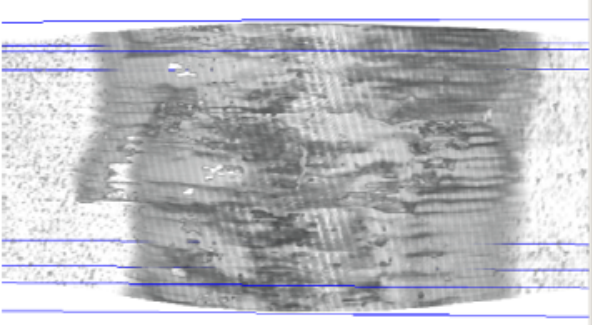

R15-UD-16-10J

Figure 12. Micro-CT images of 24 ply UD (left) and XP (right) laminates.

\section{Influence of Impact Energy and Corner Radius}

Figure 13 shows force history plots of 16 ply unidirectional laminates. The corner radius of the laminates is $6.4 \mathrm{~mm}$. Tests were conducted under different impact energy levels for the laminates having same configurations. It was found that the initial and final peak impact force increases as the impact energy level increases. The maximum displacement of the mid-point of the corner section was $35.458 \mathrm{~mm}$ and $27.814 \mathrm{~mm}$ under $13.2 \mathrm{~J}$ and $10 \mathrm{~J}$, respectively. The area damaged was $4720.5 \mathrm{~mm}^{2}$ and 9870.9 
$\mathrm{mm}^{2}$ under $10 \mathrm{~J}$ and $13.2 \mathrm{~J}$ impact energy, respectively. The area damaged under 13.2 $\mathrm{J}$ was approximately twice of the area damaged under $10 \mathrm{~J}$.
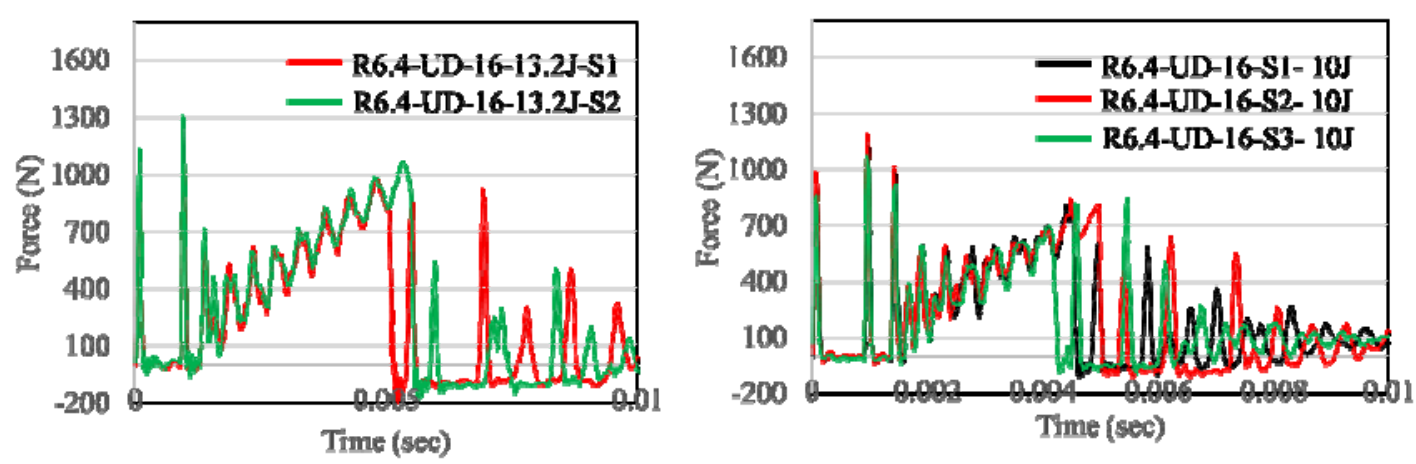

Figure 13. Low velocity impact force-time response of 16 ply UD laminates with corner radius of 6.4 $\mathrm{mm}$ subjected to 13 . $\mathrm{J}$ (left), and $10 \mathrm{~J}$ (right).

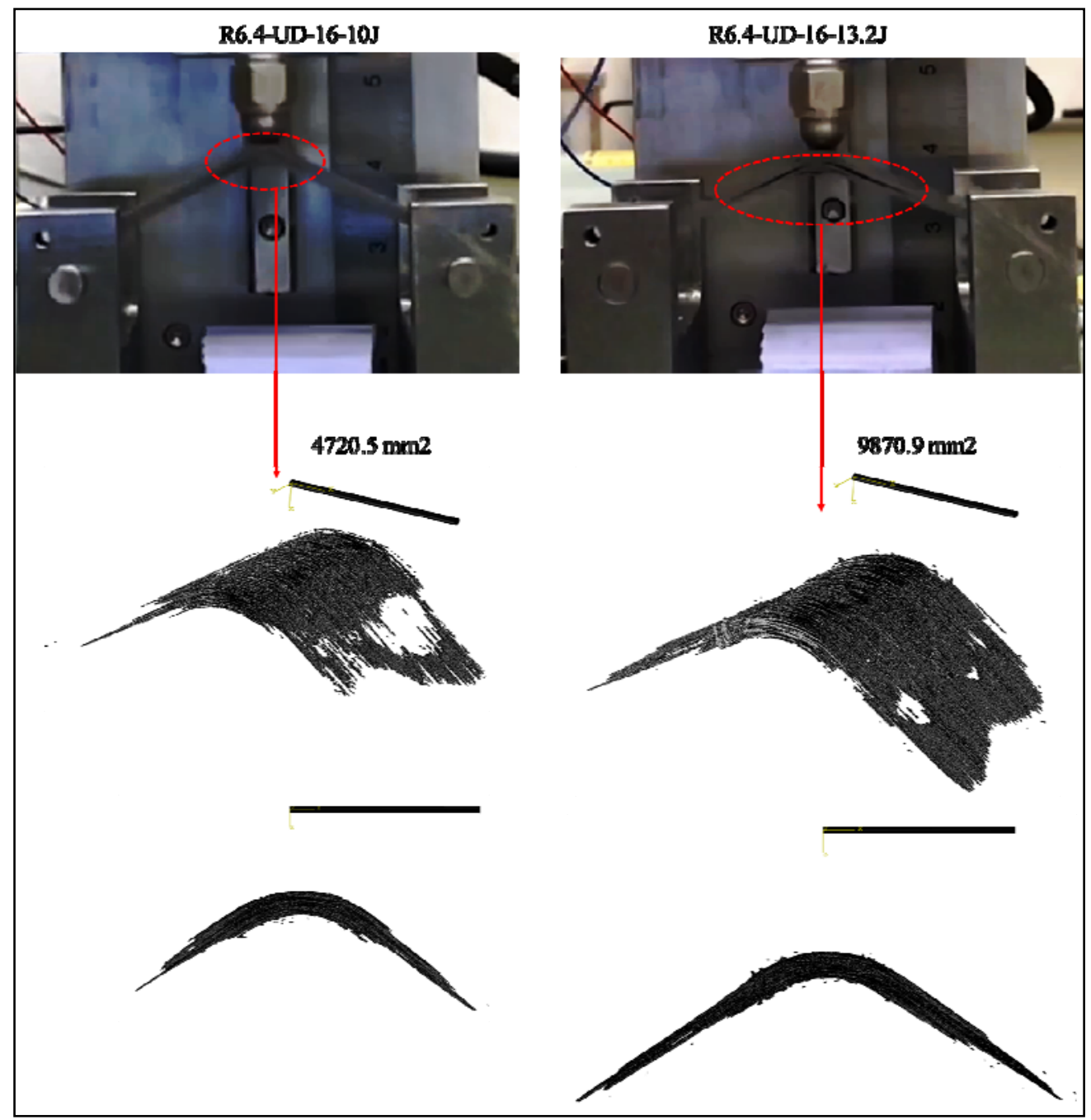

Figure 14. Region damaged for 16 ply UD laminates subjected to $10 \mathrm{~J}$ (left) and $13.2 \mathrm{~J}$ (right) impact energy. 
In order to examine the effect of corner radius on the force history, laminates having different radius were tested. Laminates having corner radius of $6.4 \mathrm{~mm}$, and 15 $\mathrm{mm}$ were compared in Figure 15 for unidirectional and cross-ply laminates. As the corner radius increased initial force peak values decreased, shown in Figure 15 and in Figure 7 . The reason behind this is that as the corner radius increases the bending stiffness of the laminate decreases. It was more flexible. Also, it should be noted that there was no sudden drop after linear region in the R15 UD laminates although the other showed sudden drop after the linear region.
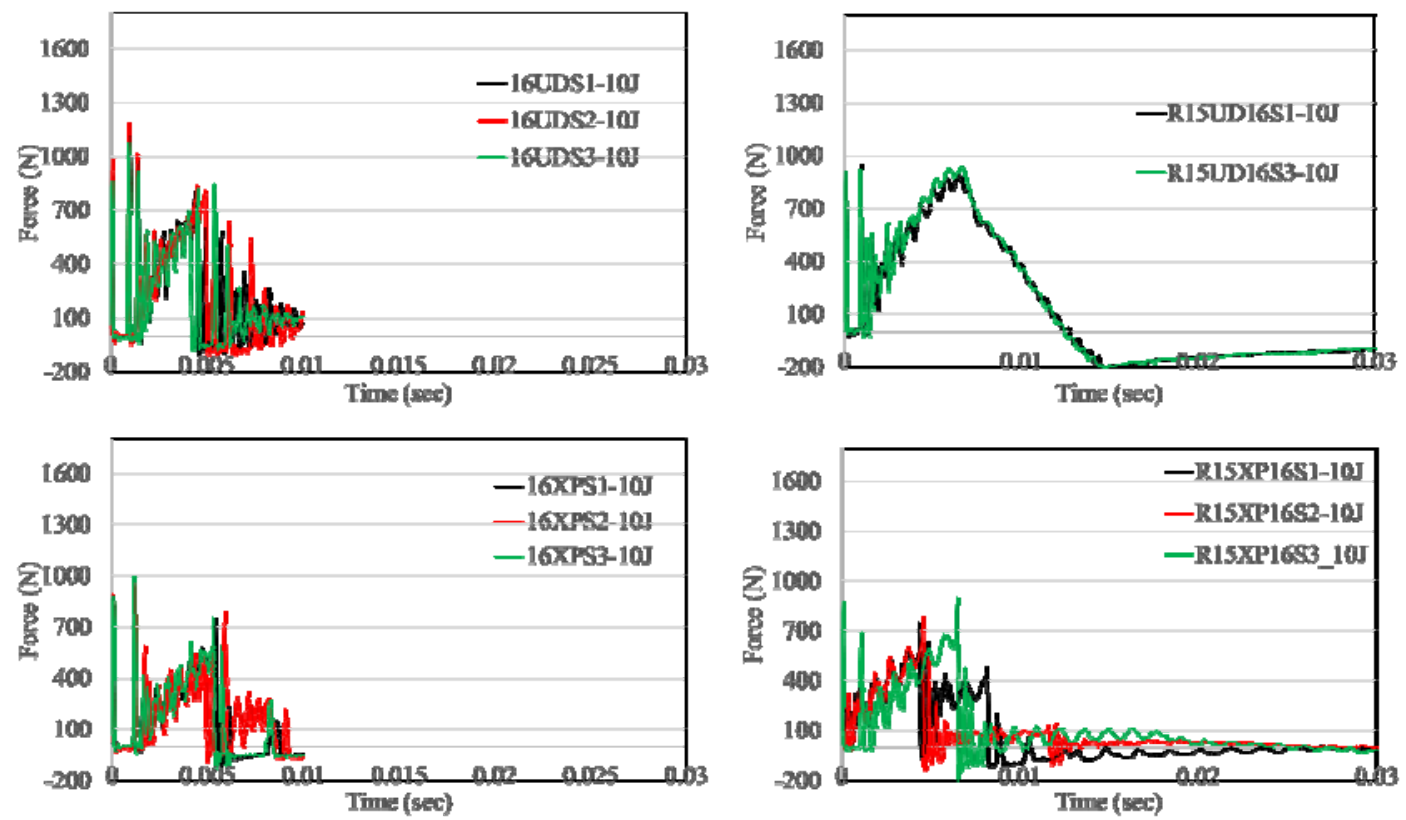

Figure 15. Low velocity impact force-time response of 16 ply UD and XP laminates with corner radius of $6.4 \mathrm{~mm}$ (left) and $15 \mathrm{~mm}$ (right) subjected to $10 \mathrm{~J}$ impact energy.

Figure 16 shows force, velocity and displacement history of 16 ply UD and XP laminates with different corner radius. The laminates were subjected to $10 \mathrm{~J}$ impact energy. The duration up to the maximum deflection for larger corner radii was smaller than those of the smaller corner radii. In UD laminates with larger corner radius there was no sudden change in the slope of velocity history. This configuration behaved much like a spring, with smaller damage inside. The deflection of laminates with smaller radius was higher than laminates with larger corner radius. The laminates with smaller corner radius sustain more damage than the laminates with larger corner radius because the impact energy is absorbed by the global deformation of the laminate; in contrast, the damage in laminates with smaller corner radius absorb the impact energy. 

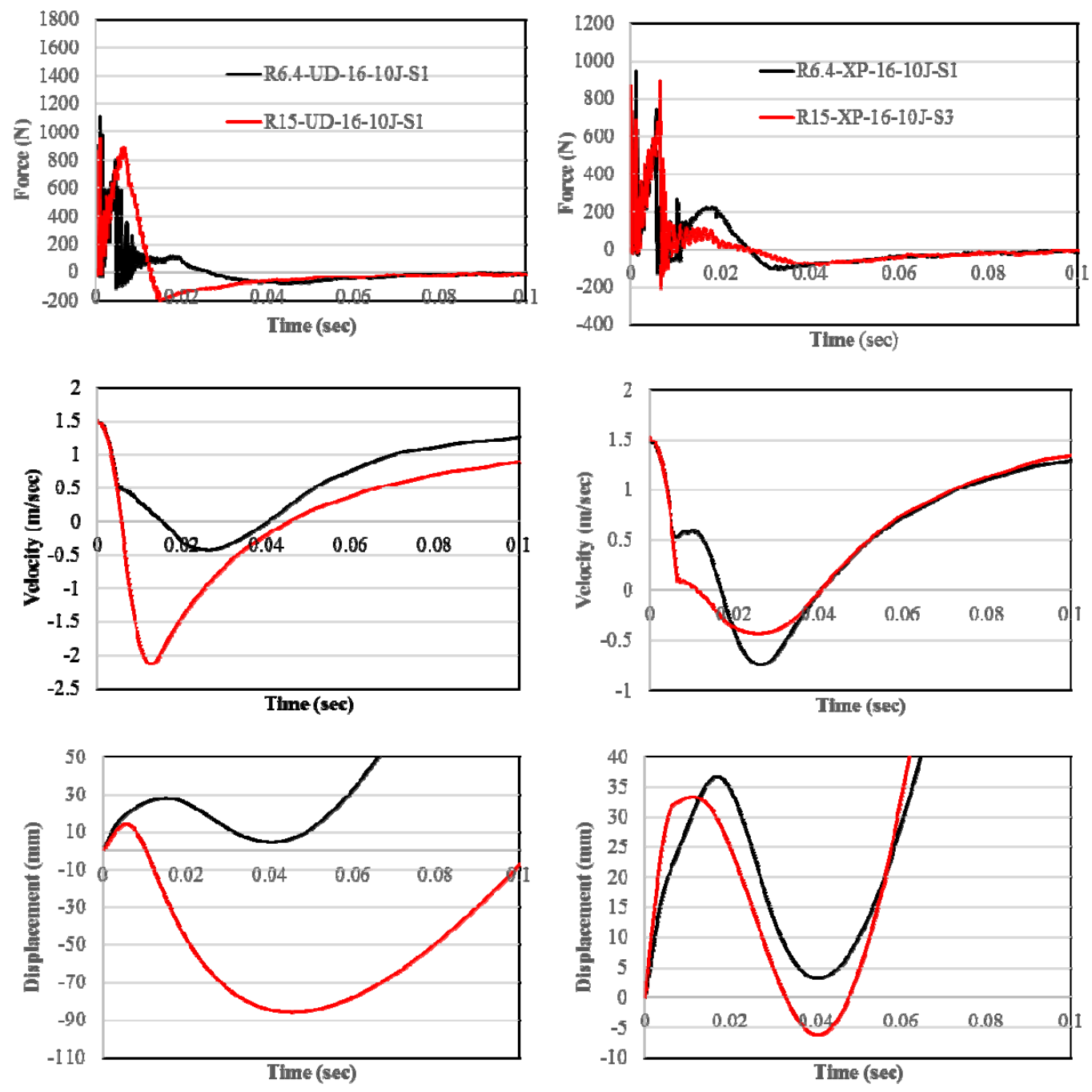

Figure 16. Force-time history of 16 ply UD (left) and 16 ply XP (right) laminates subjected to impact energy of $10 \mathrm{~J}$.

\section{Conclusions}

In this work, the effect of thickness, stacking sequence, corner radius, and impact energy level on the damage and force-time response were investigated. As the thickness decreased the deflection of the laminates increased and the duration up to the maximum deformation decreased. The maximum deformation was higher in the XP laminates but the duration up to the maximum deflection was smaller in the UD laminates as compared to the XP laminates. The damage in the UD laminates was localized at corner region while the damage extended to the arms in the XP laminates. Additionally, a "C-shape" damage, much like a wave, appeared in the arms of the XP laminates. As the corner radius increased initial peak force values decreased. The reason behind this is that as the corner radius increases the bending stiffness of the laminate decreases. It should also be noted that there was no sudden drop of force after linear region in the R15 UD laminates although R15 XP showed sudden drop after the linear region. 


\section{REFERENCES}

1. Flores M., D. Mollenhauer, V. Runatunga, T. Beberniss, D. Rapking, and M. Pankow. 2017. "Highspeed 3D Digital Image Correlation of Low-Velocity Impacts On Composite Plates," Compos. Part B., 131:153-164.

2. Sun X.C., and S.R. Hallet. 2017. "Barely Visible Impact Damage in Scaled Composite Laminates: Experiments and Numerical Simulations,” Int. J. of Impact Eng., 109:178-195.

3. Zouggar K., F.B. Boukhoulda, B. Haddag, and M. Nouari. 2016. "Numerical and Experimental Investigation of S-Glass/Polyester Composite Laminate Plate under Low Energy Impact," Compos. Part B., 89:169-186.

4. Zongjun L., A. Khennane, P.J. Hazell, and A.D Brown. 2017. "Impact Behavior of Pultruded GFRP Composites under Low-velocity Impact Loading,” Compos. Struct. 168:360-371.

5. Tang Z., C. Hang, T. Suo, Y. Wang, L. Dai, Y. Zhang, and Y. Li. 2017. "Numerical and Experimental Investigation on Hail Impact on Composite Panels," Int. J. of Impact Eng., 105:102108.

6. Karakuzu R., E. Erbil, and M. Aktas. 2010. "Impact Characterization of Glass/epoxy Composite Plates: An Experimental and Numerical Study," Compos. Part B, 41:388-395.

7. Sevkat E., B. Liaw, and F. Delale. 2013. "Drop-weight Impact Response of Hybrid Composites Impacted by Impactor of Various Geometries,” Mater. and Des., 52:67-77.

8. Gonzalez E.V., P. Maimi, P.P Camonho, A. Turon, and J.A. Mayugo. 2012. "Simulation of Dropweight and Compression after Impact Tests on Composite Laminates," Compos. Struct. 94:33643378.

9. Shi Y., T. Swait, and C. Soutis. 2012. "Modelling Damage Evolution in Composite Laminates Subjected to Low Velocity Impact,” Compos. Struct. 94:2902-2913.

10. Oiu A., K. Fu, W. Lin, C. Zhao, and Y. Tang. 2014. "Modelling low-speed Drop-weight Impact on Composite Laminates," Mater. and Des. 60:520-531.

11. Tan W., B. G. Falzon, L.N.S. Chiu, and M. Price. 2015. "Predicting Low Velocity Impact Damage and Compression-after-impact (CAI) Behavior of Composite Laminates," Compsos. Part A. 71:212-226.

12. Liu J., W. He, D. Xe, and B. Tao. 2017. "The effect of Impactor Shape on the Low-velocity Impact Behavior of Hybrid Corrugated Core Sandwich Structures," Compsos. Part B. 111:315-331.

13. Wimmer G., W. Kitzmuller, G. Pinter, T. Wettemann, and H.E. Pettermann. 2009. "Computational and Experimental Investigation of Delamination in L-shaped Composite Componenets," Eng. Frac. Mech., 76:2810-2820.

14. Most J., D. Stegmair, and D. Petry. 2015. "Error Estimation Between Simple, Closed-form Analystical Formules and Full-scale FEM for Interlaminar Stress Prediction in Curved Laminates," Compos. Struct., 131:72-81.

15. Ranz D., J. Cuartero, A. Miravete, and R. Miralbes. 2017. "Experimental Research into Interlaminar Tensile Strength of Carbon/epoxy Curved Beams," Compos. Struct., 164:189-197.

16. Gozluklu B., I. Uyar, and D. Coker. 2015. "Intersonic Delamination in Curved Thick Composite Laminates under Quasi-static Loading," Mech. of Mater., 80:163-182.

17. Saghafi H., G. Minak, and A. Zucchelli. 2014. "Effect of Preload on the Impact Response of Curved Composite Panels," Compos. Part B, 60:74-81.

18. Kistler L.S., and A.M. Waas. 1999. “On The Response of Curved Laminated Panels Subjected to Transverse Impact Loads,” Int. J. Solids Struct. 36(9):1311-1327.

19. Kistler L.S., and A.M. Waas. 1998. "Impact Response of Cylindrically Curved Laminates Including a Large Deformation Scaling Study," Int. J. of Impact Eng., 21(1-2):61-75.

20. Kistler L.S., and A.M. Waas. 1998. "Experiment and Analysis on the Response of Curved Laminated Composite Panels Subjected to Low Velocity Impact,” Int. J. of Impact Eng., 21(9):711736.

21. Hao W., Y. Yuan, J. Zhu, and L. Chen. 2016. "Effect of Impact Damage on the Curved Beam Interlaminar Stregth of Carbon/epoxy Laminates," J. of Adhes Sci. and Technol., 30(11):1189-1200. 